\title{
Vibrational spectroscopic study of poldervaartite $\mathrm{CaCa}\left[\mathrm{SiO}_{3}(\mathrm{OH})(\mathrm{OH})\right]$
}

\author{
Ray L. Frost ${ }^{\mathrm{a}, *}$, Andrés López ${ }^{\mathrm{a}}$, Ricardo Scholz ${ }^{\mathrm{b}}$, Rosa Malena Fernandes Lima ${ }^{\mathrm{c}}$

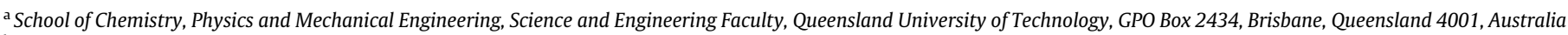 \\ ${ }^{b}$ Geology Department, School of Mines, Federal University of Ouro Preto, Campus Morro do Cruzeiro, Ouro Preto, MG 35,400-00, Brazil \\ ${ }^{\mathrm{c}}$ Mining Engineering Department, School of Mines, Federal University of Ouro Preto, Campus Morro do Cruzeiro, Ouro Preto, MG 35,400-00, Brazil
}

\section{H I G H L I G H T S}

- We have studied the structure of the mineral poldervaartite

$\mathrm{CaCa}\left[\mathrm{SiO}_{3}(\mathrm{OH})\right](\mathrm{OH})$.

- It forms a series with its manganese analogue olmiite

$\mathrm{CaMn}\left[\mathrm{SiO}_{3}(\mathrm{OH})\right](\mathrm{OH})$.

- We used scanning electron microscopy, thermogravimetric analysis, Raman and infrared spectroscopy.

- Thermogravimetric analysis proves the mineral decomposes at $485{ }^{\circ} \mathrm{C}$ with a mass loss of $7.6 \%$.

- Vibrational spectroscopy enables a detailed assessment of the molecular structure of poldervaartite.

\section{A R T I C L E I N F O}

Article history:

Received 14 July 2014

Received in revised form 25 August 2014

Accepted 11 September 2014

Available online 22 September 2014

\section{Keywords:}

Poldervaartite

Silicate

Thermogravimetric analyses

Scanning electron microscopy

Infrared and Raman spectroscopy

\section{G R A P H I C A L A B S T R A C T}

\begin{abstract}
A B S T R A C T
We have studied the mineral poldervaartite $\mathrm{CaCa}\left[\mathrm{SiO}_{3}(\mathrm{OH})(\mathrm{OH})\right]$ which forms a series with its manganese analogue olmiite $\mathrm{CaMn}\left[\mathrm{SiO}_{3}(\mathrm{OH})\right](\mathrm{OH})$ using a range of techniques including scanning electron microscopy, thermogravimetric analysis, Raman and infrared spectroscopy. Chemical analysis shows the mineral is reasonably pure and contains only calcium and manganese with low amounts of $\mathrm{Al}$ and F. Thermogravimetric analysis proves the mineral decomposes at $485{ }^{\circ} \mathrm{C}$ with a mass loss of $7.6 \%$ compared with the theoretical mass loss of $7.7 \%$. A strong Raman band at $852 \mathrm{~cm}^{-1}$ is assigned to the $\mathrm{SiO}$ stretching vibration of the $\mathrm{SiO}_{3}(\mathrm{OH})$ units. Two Raman bands at 914 and $953 \mathrm{~cm}^{-1}$ are attributed to the antisymmetric vibrations. Intense prominent peaks observed at $3487,3502,3509,3521$ and $3547 \mathrm{~cm}^{-1}$ are assigned to the $\mathrm{OH}$ stretching vibration of the $\mathrm{SiO}_{3}(\mathrm{OH})$ units. The observation of multiple $\mathrm{OH}$ bands supports the concept of the non-equivalence of the $\mathrm{OH}$ units. Vibrational spectroscopy enables a detailed assessment of the molecular structure of poldervaartite.
\end{abstract}

(c) 2014 Elsevier B.V. All rights reserved.

\section{Introduction}

The mineral poldervaartite $\mathrm{CaCa}\left[\mathrm{SiO}_{3}(\mathrm{OH})(\mathrm{OH})\right]$ is a silicate mineral of calcium [1]. Sometimes, the formula is written as $\left(\mathrm{Ca}, \mathrm{Mn}_{2}^{2+}\right.$ $\mathrm{SiO}_{3}(\mathrm{OH})_{2}$. The Mn dominant analogue of poldervaartite is olmiite [2].

\footnotetext{
* Corresponding author. Tel.: +61 73138 2407; fax: +61 731381804 . E-mail address: r.frost@qut.edu.au (R.L. Frost).
}

The mineral poldervaartite $\mathrm{CaCa}\left[\mathrm{SiO}_{3}(\mathrm{OH})\right](\mathrm{OH})$, forms a series with olmiite, ideally $\left.\mathrm{CaMn}_{\mathrm{SiO}}(\mathrm{OH})\right](\mathrm{OH})$, its $\mathrm{Mn}$ analogue - $[1,3]$. The chemical formula of olmiite [4] is correctly calculated from the EPMA data $(\mathrm{Mn}>0.5$ and $\mathrm{Ca}<1.5$ atom per formula unit (a.p.f.u.)). For the mineral chemistry of poldervaartite ( $\mathrm{Ca}>1.5$ and $\mathrm{Mn}<0.5$ a.p.f.u). This mineral was first found in South Africa at the N'Chwaning II mine of the Kalahari manganese fields and occurs as a product of hydrothermal alteration of primary sedimentary and low-grade 
metamorphic ores in a temperature range from $250{ }^{\circ} \mathrm{C}$ to $400^{\circ} \mathrm{C}$. Usually, poldervaartite occurs in association with celestine, bultfonteinite, olmiite, sturmanite and hematite [1,3].

The mineral is orthorhombic with point group: $2 / \mathrm{m} 2 / \mathrm{m} 2 / \mathrm{m}$. The mineral occurs as wheat-sheaf aggregates with a crystal length reaching up to $7 \mathrm{~mm}$. The space group is Pbca with $a=9.398(1)$, $b=9.139(2), c=10.535(2) \AA$ and $Z=8$. Olmiite crystallizes in the orthorhombic crystal system, with unit cell parameters $a=9.243(3), b=9.076(9), c=10.342(9) \AA . \quad V=868(1) \AA^{3}[1,3]$. The atomic arrangement of poldervaartite is similar to that of olmiite. Variations in bond distances and angles are related to the pronounced difference in the Ca and Mn content. The structure of both poldervaartite and olmiite can be schematically described, for convenience, as a sequence along [010] of alternating layers containing $\mathrm{M} 2+\mathrm{Si}$ and $\mathrm{M} 1$ polyhedra, respectively. Nonetheless, the strong three-dimensional linkage among the polyhedral units results in a rather isotropic framework, as pointed out by Dai $[1,3]$. Olmiite consists of isolated $\mathrm{SiO}_{3}(\mathrm{OH})$ tetrahedra continuously connected along the [100] direction to two $\mathrm{M}_{2} \mathrm{O}_{7}$ polyhedra by sharing edges. The M2-Si chains are linked together by corner sharing to form waved sheets parallel to $(010)$. Alternating sheets are linked together by M1 octahedra and hydrogen bonds, resulting in a strongly bonded polyhedral network $[1,3]$.

Recently, the authors undertook a study of the mineral olmiite [4]. In this work, we have studied the mineral poldervaartite $\mathrm{CaCa}$ $[\mathrm{SiO} 3(\mathrm{OH})(\mathrm{OH})]$ using scanning electron microscopy, thermogravimetric analyses and vibrational spectroscopy. The combination of scanning electron microscopy (SEM) and vibrational spectroscopy has proven a success for the study of the chemistry and molecular structure of minerals [5-10]. In this work we also related the Raman and FTIR spectra of poldervaartite to the structure of the mineral.

\section{Experimental}

\section{Samples description and preparation}

The poldervaartite sample studied in this work was obtained from the collection of the Geology Department of the Federal University of Ouro Preto, Minas Gerais, Brazil, with sample code SAD-041. The sample is from the type locality in N' Chwaning II mine of the Kalahari manganese fields, South Africa. The mineral occurs in association with calcite and manganese oxides.

The compositions have been reported by Anthony et al. (page 192) [11]. The sample was gently crushed and the associated minerals were removed under a stereomicroscope Leica MZ4. Qualitative and semiquantitative chemical analysis via SEM/EDS were applied to the mineral characterization.

\section{Scanning electron microscopy (SEM)}

Experiments and analyses involving electron microscopy were performed in the centre of Microscopy of the Universidade Federal de Minas Gerais, Belo Horizonte, Minas Gerais, Brazil (http:// www.microscopia.ufmg.br).

Poldervaartite crystals were coated with a $5 \mathrm{~nm}$ layer of evaporated carbon. Secondary Electron and Backscattered Electron images were obtained using a JEOL JSM-6360LV equipment. Qualitative and semi-quantitative chemical analyses in the SEM/EDS mode were performed with a ThermoNORAN spectrometer model Quest and was applied to support the mineral characterization.

\section{Thermogravimetric analysis - TG/DTG}

Thermogravimetric analysis of the poldervaartite mineral was obtained by using TA Instruments Inc. Q50 high-resolution TGA operating at a $10^{\circ} \mathrm{C} / \mathrm{min}$ ramp with data sample interval of $0.50 \mathrm{~s} / \mathrm{pt}$ from room temperature to $1000^{\circ} \mathrm{C}$ in a high-purity flowing nitrogen atmosphere $\left(100 \mathrm{~cm}^{3} / \mathrm{min}\right)$. A total mass of $41.92 \mathrm{mg}$ of finely ground samples was heated in an open platinum crucible.

\section{Raman microprobe spectroscopy}

Crystals of poldervaartite were placed on a polished metal surface on the stage of an Olympus BHSM microscope, which is equipped with $10 \times, 20 \times$, and $50 \times$ objectives. The microscope is part of a Renishaw 1000 Raman microscope system, which also includes a monochromator, a filter system and a CCD detector (1024 pixels). The Raman spectra were excited by a Spectra-Physics model 127 He-Ne laser producing highly polarized light at $633 \mathrm{~nm}$ and collected at a nominal resolution of $2 \mathrm{~cm}^{-1}$ and a precision of $\pm 1 \mathrm{~cm}^{-1}$ in the range between 200 and $4000 \mathrm{~cm}^{-1}$. Repeated acquisitions on the crystals using the highest magnification $(50 \times)$ were accumulated to improve the signal to noise ratio of the spectra. Raman Spectra were calibrated using the $520.5 \mathrm{~cm}^{-1}$ line of a silicon wafer. The Raman spectrum of at least 10 crystals was collected to ensure the consistency of the spectra.

An image of the poldervaartite crystals measured is shown in the graphical abstract. Clearly the crystals of poldervaartite are readily observed, making the Raman spectroscopic measurements readily obtainable.

\section{Infrared spectroscopy}

Infrared spectra of poldervaartite were obtained using a Nicolet Nexus 870 FTIR spectrometer with a smart endurance single bounce diamond ATR cell. Spectra over the $500-4000 \mathrm{~cm}^{-1}$ range were obtained by the co-addition of 128 scans with a resolution of $4 \mathrm{~cm}^{-1}$ and a mirror velocity of $0.6329 \mathrm{~cm} / \mathrm{s}$. Spectra were coadded to improve the signal to noise ratio.

Spectral manipulation such as baseline correction/adjustment and smoothing were performed using the Spectracalc software package GRAMS (Galactic Industries Corporation, NH, USA). Band component analysis was undertaken using the Jandel 'Peakfit' software package that enabled the type of fitting function to be selected and allows specific parameters to be fixed or varied accordingly. Band fitting was done using a Lorentzian-Gaussian cross-product function with the minimum number of component bands used for the fitting process. The Lorentzian-Gaussian ratio was maintained at values greater than 0.7 and fitting was undertaken until reproducible results were obtained with squared correlations of $r^{2}$ greater than 0.995 .

\section{Results and discussion}

\section{Chemical characterization}

The SEM image of poldervaartite sample studied in this work is shown in Fig. 1. The image shows a poldervaartite crystal aggregate. The mineral occurs in association with small amounts of manganese oxides. Qualitative chemical analysis shows a $\mathrm{Ca}$ and $\mathrm{Mn}$ silicate (Fig. 2). Traces of $\mathrm{Al}$ and $\mathrm{F}$ were noted. No other elements were detected. The chemical analysis of olmiite shows a Ca and Mn silicate [4].

\section{Thermal analysis}

The thermal analysis of poldervaartite is given in the supplementary information as Fig. S1. Two mass loss steps are observed at $485^{\circ} \mathrm{C}$ and $722{ }^{\circ} \mathrm{C}$ with mass losses of 5.4 and $1.3 \%$. 


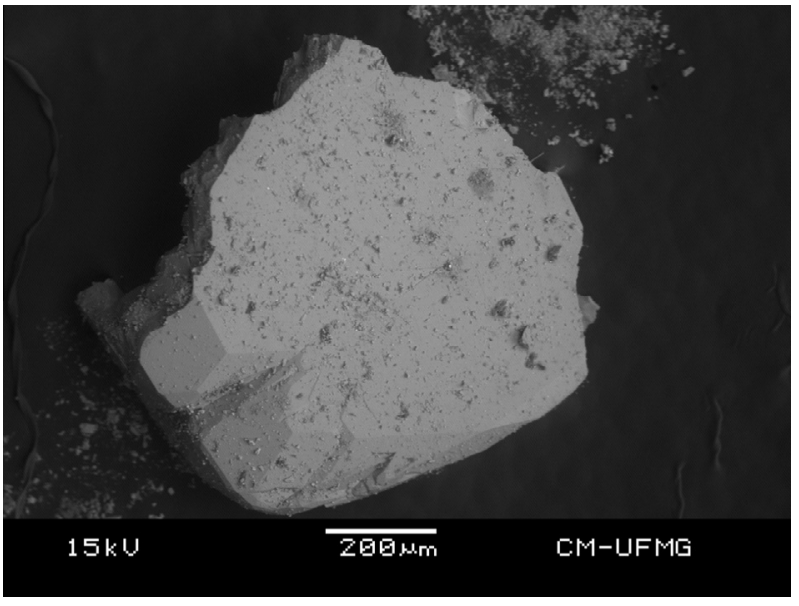

Fig. 1. Backscattered electron (BSE) image of a poldervaartite crystal aggregate up to $0.5 \mathrm{~mm}$ in length.

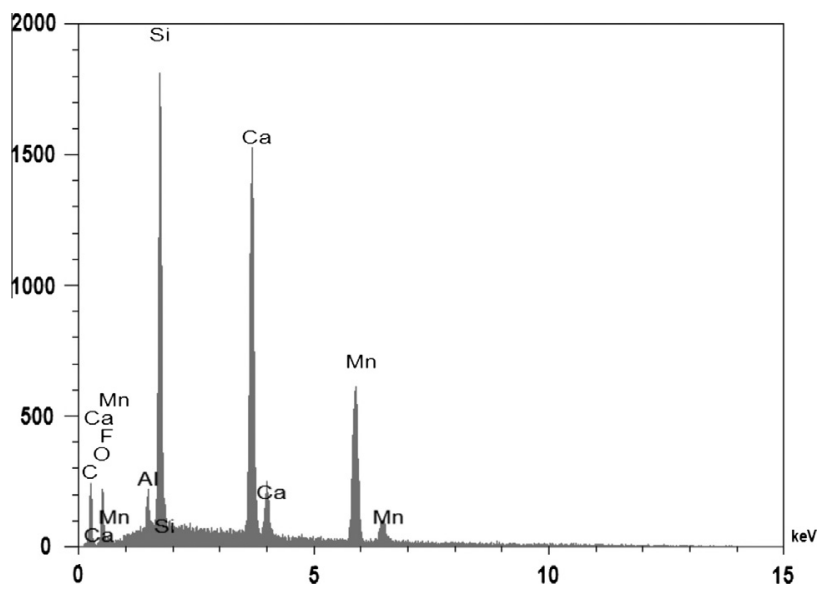

Fig. 2. EDS analysis of poldervaartite.

The temperature range for the mass loss is very narrow. The following chemical reaction is proposed for the thermal decomposition of poldervaartite:

$\mathrm{CaMn}\left[\mathrm{SiO}_{3}(\mathrm{OH})\right](\mathrm{OH}) \rightarrow \mathrm{CaMnSiO}_{4}+\mathrm{H}_{2} \mathrm{O}$

\section{Vibrational spectroscopy}

\section{Vibrational spectroscopy of poldervaartite}

The Raman spectrum of poldervaartite in the $100-4000 \mathrm{~cm}^{-1}$ spectral range is displayed in Fig. 3a. This spectrum shows the position and relative intensities of the Raman bands. It is noted that there are large parts of the spectrum where no intensity or minimal intensity is observed. Thus, the spectrum is subdivided into subsections depending upon the type of vibration being studied. The infrared spectrum of poldervaartite in the $500-4000 \mathrm{~cm}^{-1}$ spectral region is shown in Fig. $3 \mathrm{~b}$. This figure shows the position of the infrared bands and their relative intensities. As for the Raman spectrum, there are parts of the spectrum where little or no intensity is observed.

The Raman spectrum of poldervaartite over the $700-1000 \mathrm{~cm}^{-1}$ spectral range is shown in Fig. 4a. The Raman spectrum is dominated by an intense peak at $852 \mathrm{~cm}^{-1}$. Dowty showed that the $\mathrm{SiO}_{3}$ units had a unique band position of $980 \mathrm{~cm}^{-1}$ [12] (see Figs. 2 and 4 of this
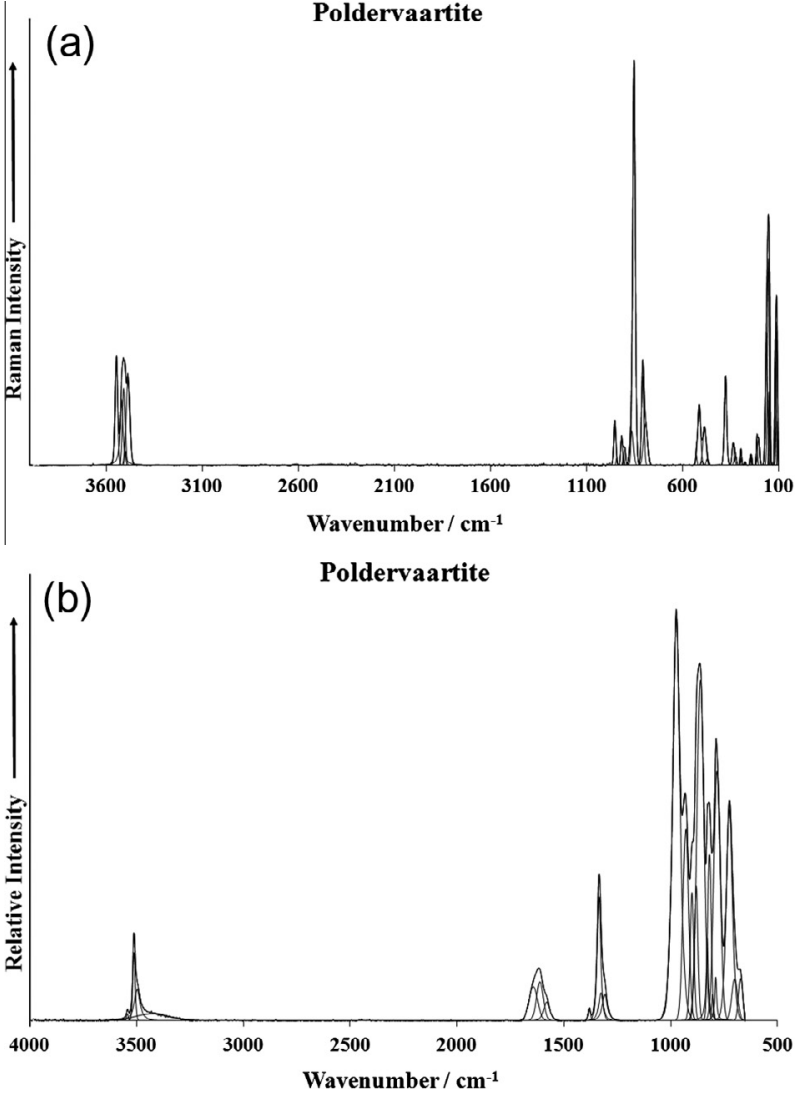

Fig. 3. (a) Raman spectrum of poldervaartite over the $100-4000 \mathrm{~cm}^{-1}$ spectral range (upper spectrum). (b) Infrared spectrum of poldervaartite over the 500$4000 \mathrm{~cm}^{-1}$ spectral range (lower spectrum).

reference). Dowty also showed that $\mathrm{Si}_{2} \mathrm{O}_{5}$ units had a Raman peak at around $1100 \mathrm{~cm}^{-1}$. Poldervaartite consists of isolated $\mathrm{SiO}_{3}(\mathrm{OH})$ tetrahedra continuously connected along the [100] direction to two $\mathrm{M}_{2} \mathrm{O}_{7}$ polyhedra by sharing edges. The $\mathrm{M} 2-\mathrm{Si}$ chains are linked together by corner sharing to form waved sheets parallel to $(010)$. Alternating sheets are linked together by M1 octahedra and hydrogen bonds, resulting in a strongly bonded polyhedral network $[1,3]$. Thus, the Raman peak at $852 \mathrm{~cm}^{-1}$ is assigned to the $\mathrm{SiO}$ stretching vibration of the $\mathrm{SiO}_{3}(\mathrm{OH})$ units. In the Raman spectrum of olmiite [4] the band position was found at $853 \mathrm{~cm}^{-1}$. The two bands of poldervaartite at 900 and $917 \mathrm{~cm}^{-1}$ with a low intensity shoulder at $907 \mathrm{~cm}^{-1}$ are attributed to the antisymmetric vibrations of the $\mathrm{SiO}_{3}(\mathrm{OH})$ units. The position of these bands for olmiite [4] were found at 914 and $953 \mathrm{~cm}^{-1}$. The two Raman bands of poldervaartite at 792 and $807 \mathrm{~cm}^{-1}$ are attributed to the SiOH deformation modes. These two bands were found for olmiite [4] at 799 and $811 \mathrm{~cm}^{-1}$

The infrared spectrum of poldervaartite over the 650 to $1050 \mathrm{~cm}^{-1}$ spectral range is shown in Fig. 4b. Strong infrared bands are observed at 858 and $970 \mathrm{~cm}^{-1}$. This latter band together with the infrared bands at 877,897 and $926 \mathrm{~cm}^{-1}$ are assigned to the $\mathrm{SiO}$ antisymmetric stretching vibrations. The infrared band at $858 \mathrm{~cm}^{-1}$ is ascribed to the SiO symmetric stretching band. Other infrared bands are observed at 780, 786, 800 and $815 \mathrm{~cm}^{-1}$. If we follow the assignment of the Raman bands, then these bands are due to hydroxyl deformation modes.

The Raman spectra over the $400-600 \mathrm{~cm}^{-1}$ spectral range and over the $100-250 \mathrm{~cm}^{-1}$ spectral range are presented in Fig. 5. Raman bands noted at 485 and $513 \mathrm{~cm}^{-1}$ are assigned to OSiO bending modes. Dowty calculated the band position of these bending modes for different siloxane units [12] and demonstrated the 

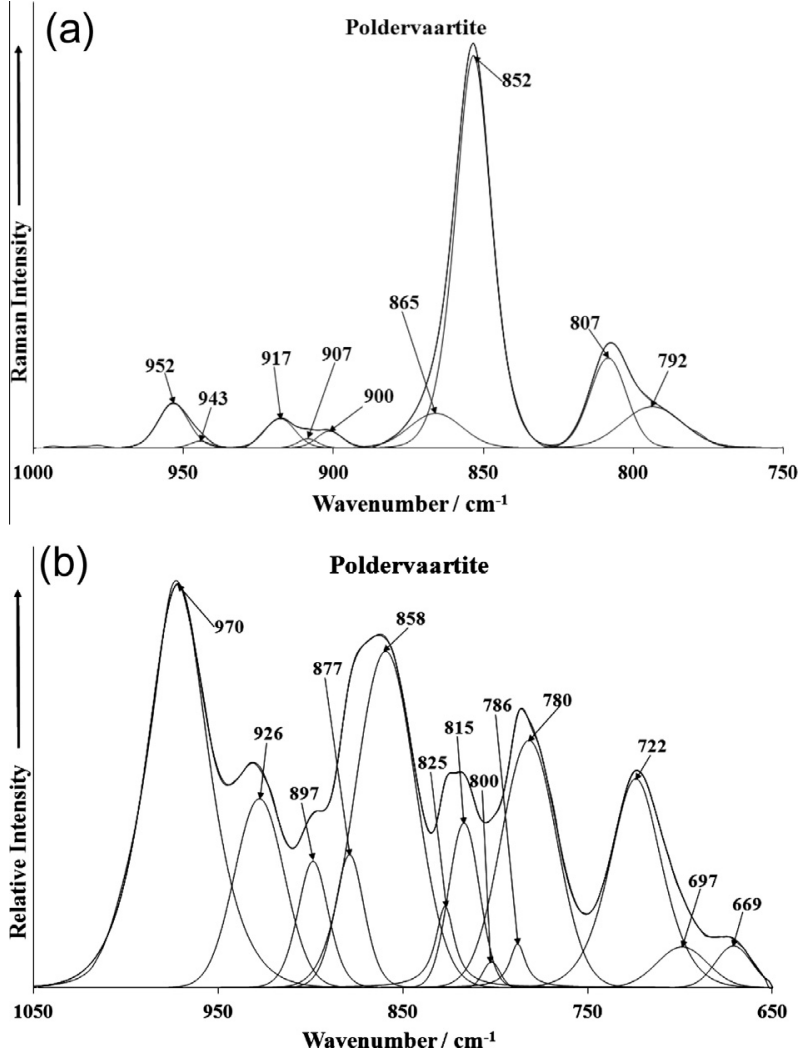

Fig. 4. (a) Raman spectrum of poldervaartite (upper spectrum) over the 1000$1150 \mathrm{~cm}^{-1}$ spectral range and (b) infrared spectrum of poldervaartite (lower spectrum) over the $650-1150 \mathrm{~cm}^{-1}$ spectral range.
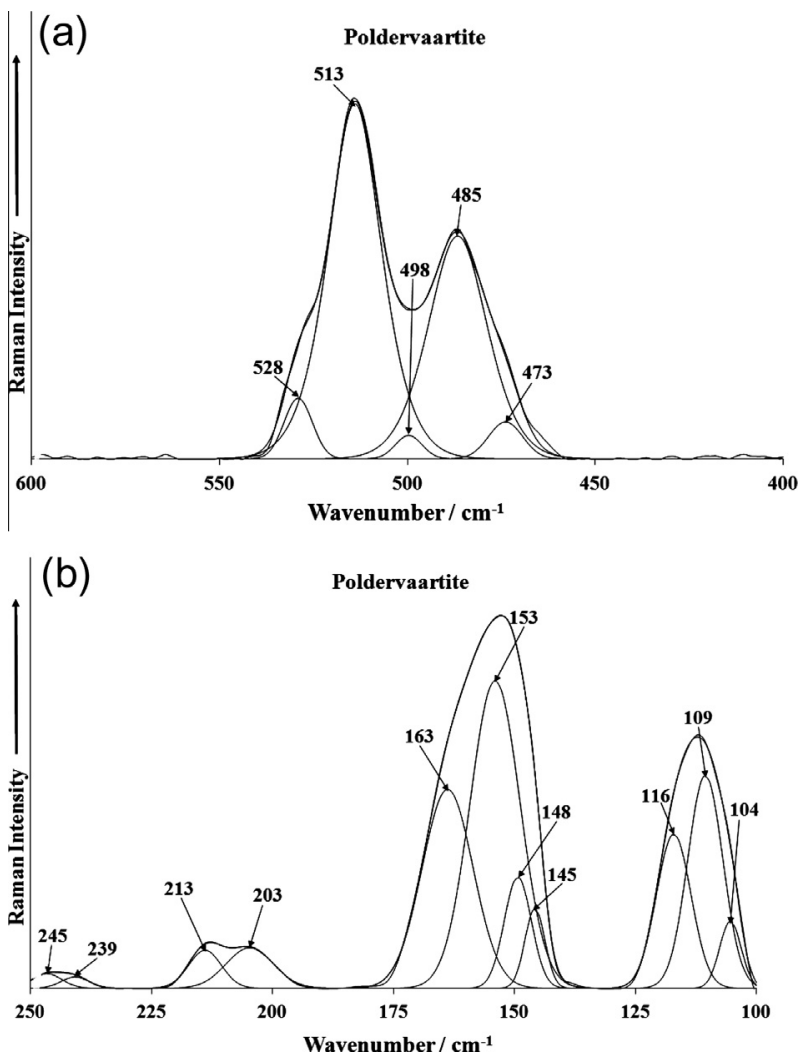

Fig. 5. (a) Raman spectrum of poldervaartite (upper spectrum) over the 400$800 \mathrm{~cm}^{-1}$ spectral range and (b) Raman spectrum of poldervaartite (lower spectrum) over the $100-400 \mathrm{~cm}^{-1}$ spectral range.
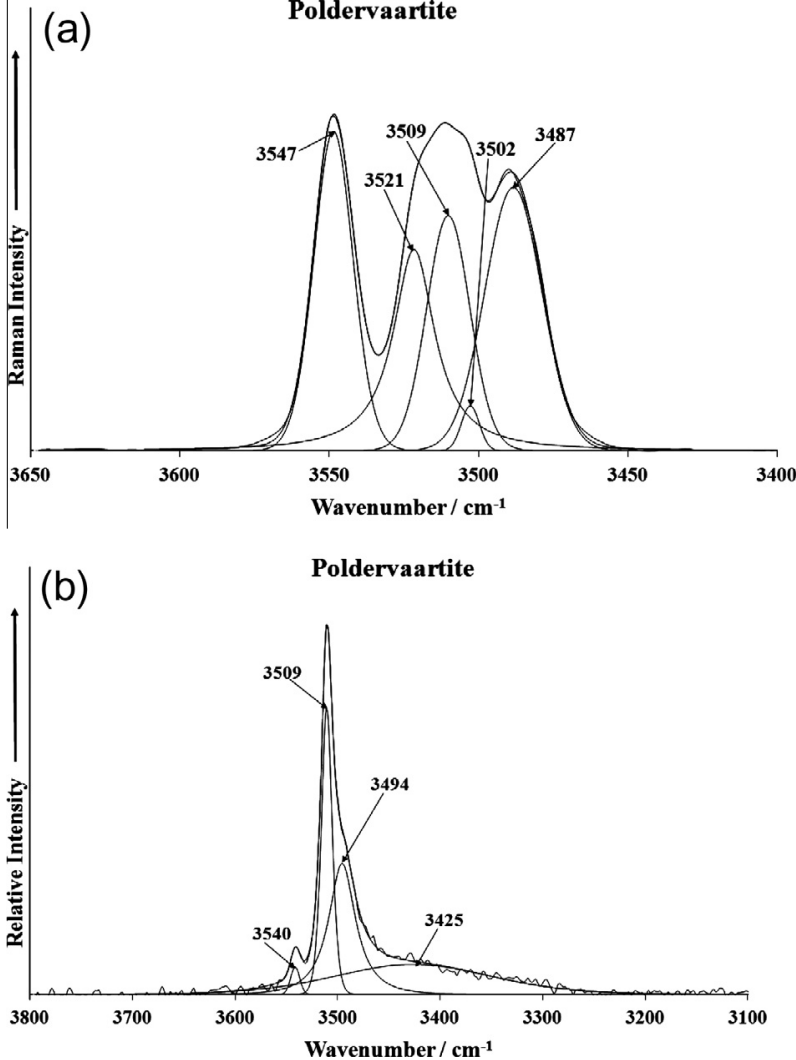

Fig. 6. (a) Raman spectrum of poldervaartite (upper spectrum) over the 2800$4000 \mathrm{~cm}^{-1}$ spectral range and (b) infrared spectrum of poldervaartite (lower spectrum) over the $2800-3800 \mathrm{~cm}^{-1}$ spectral range.

band position of the bending modes for $\mathrm{SiO}_{3}$ units is located at around $650 \mathrm{~cm}^{-1}$. This calculated value is in harmony with the higher wavenumber band observed at $663 \mathrm{~cm}^{-1}$ as calculated by Dowty. According to Adams et al. [13], the band at $432 \mathrm{~cm}^{-1}$ is due to the coincidence of both the $B_{2 g}$ and $E_{g}$ modes. Raman bands are observed in the far low wavenumber region at 104, 109, 116, $145,148,153,163,203,213 \mathrm{~cm}^{-1}$. These bands are simply described as lattice vibrations.

The Raman spectrum of poldervaartite over the $3400-3650 \mathrm{~cm}^{-1}$ spectral range is reported in Fig. 6a. Prominent peaks are observed at $3487,3502,3509,3521$ and $3547 \mathrm{~cm}^{-1}$. These bands are assigned to the $\mathrm{OH}$ stretching vibration of the $\mathrm{SiO}_{3}(\mathrm{OH})$ units. The observation of multiple bands proves that the $\mathrm{OH}$ groups are not equivalent

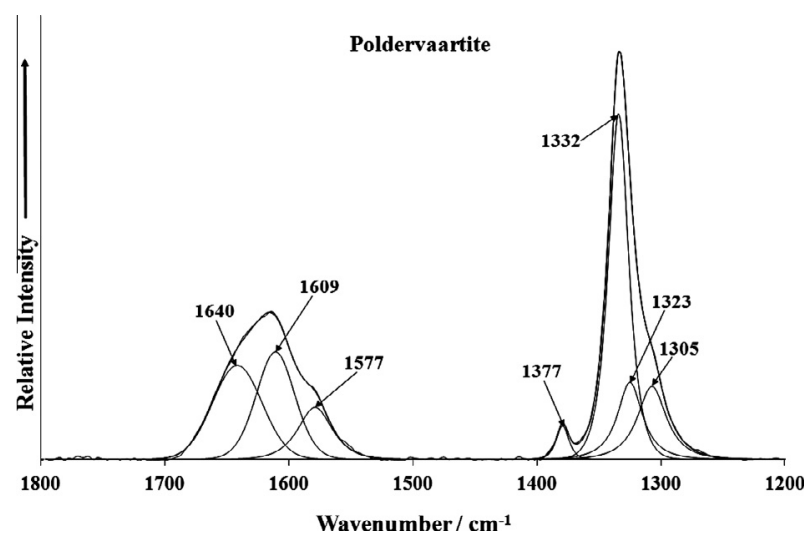

Fig. 7. Infrared spectrum of poldervaartite over the $1200-1800 \mathrm{~cm}^{-1}$ spectral range. 
in the poldervaartite structure. The infrared spectrum of poldervaartite over the $3000-3800 \mathrm{~cm}^{-1}$ spectral range is shown in Fig. 6b. Infrared bands are found at 3494,3509 and $3540 \mathrm{~cm}^{-1}$ with a broad shoulder at $3425 \mathrm{~cm}^{-1}$. The infrared bands support the concept of the non-equivalence of the $\mathrm{OH}$ units in the poldervaartite structure. The broad feature may be ascribed to water stretching modes; however, no water bending mode was observed in the infrared spectrum in the $1500-1800 \mathrm{~cm}^{-1}$ spectral range. Some infrared bands were observed in the $1200-1800 \mathrm{~cm}^{-1}$ spectral range (Fig. 7). Infrared bands are observed at 1305, 1323, 1332 and $1377 \mathrm{~cm}^{-1}$. These bands are all related to $\mathrm{SiO}$ vibrations. Infrared bands are observed at 1609 and $1640 \mathrm{~cm}^{-1}$ and are probably due to water bending modes.

\section{Conclusions}

We have studied the mineral poldervaartite $\mathrm{CaCa}\left[\mathrm{SiO}_{3}\right.$ $(\mathrm{OH})](\mathrm{OH})$ which forms a continuous series with its manganese analogue olmiite $\left.\mathrm{CaMn}_{\mathrm{SiO}}(\mathrm{OH})\right](\mathrm{OH})$ using a combination of electron microscopy with EDS analysis, thermogravimetric analysis, infrared and Raman spectroscopy. These temperatures are below the thermal decomposition of poldervaartite of $502^{\circ} \mathrm{C}$.

Raman spectroscopy identifies a peak at $852 \mathrm{~cm}^{-1}$ assigned to the $\mathrm{SiO}$ stretching vibration of the $\mathrm{SiO}_{3}(\mathrm{OH})$ units. Strong infrared bands observed at 858 and $970 \mathrm{~cm}^{-1}$ are assigned to this vibration. Prominent peaks are observed at 3487, 3502, 3509, 3521 and $3547 \mathrm{~cm}^{-1}$ and are assigned to the $\mathrm{OH}$ stretching vibration of the $\mathrm{SiO}_{3}(\mathrm{OH})$ units. The equivalent infrared bands found at 3494, 3509 and $3540 \mathrm{~cm}^{-1}$ supports the concept of the non-equivalence of the $\mathrm{OH}$ units in the poldervaartite structure. Vibrational spectroscopy enables a detailed assessment of the molecular structure of poldervaartite to be attained.

\section{Acknowledgements}

The financial and infra-structure support of the Discipline of Nanotechnology and Molecular Science, Science and Engineering Faculty of the Queensland University of Technology, is gratefully acknowledged. The Australian Research Council (ARC) is thanked for funding the instrumentation.

\section{Appendix A. Supplementary material}

Supplementary data associated with this article can be found, in the online version, at http://dx.doi.org/10.1016/j.saa.2014.09.017.

\section{References}

[1] Y. Dai, G.E. Harlow, A.R. McGhie, Am. Min. 78 (1993) 1082-1087.

[2] P. Bonazzi, L. Bindi, O. Medenbach, R. Pagano, G.I. Lampronti, S. Menchetti, Min, Mag. 71 (2007) 193-201.

[3] R. Pagano, A. Guastoni, F. Pezzotta, Min. Rec. 39 (2008) 373-381.

[4] R.L. Frost, R. Scholz, A. Lopez, Y. Xi, A. Granja, Z. Zigovecki Gobac, R.M.F. Lima, J. Mol. Struct. 1053 (2013) 22-26.

[5] R.L. Frost, A. Lopez, R. Scholz, Y. Xi, C. Lana, Spectrochim. Acta, Part A 128 (2014) 408-412.

[6] R.L. Frost, A. Lopez, R. Scholz, Y. Xi, J. Mol. Struct. 1059 (2014) 40-43.

[7] R.L. Frost, A. Lopez, R. Scholz, Y. Xi, Spectrochim. Acta, Part A (2014) (ahead of print).

[8] R.L. Frost, A. Lopez, F.M. Belotti, Y. Xi, R. Scholz, Spectrochim. Acta, Part A 127 (2014) 243-247.

[9] R.L. Frost, R. Scholz, A. Lopez, Y. Xi, S. Queiroz Camila de, M. Belotti Fernanda, M. Candido Filho, Spectrochim. Acta, Part A 118 (2014) 430-437.

[10] R.L. Frost, A. Lopez, Y. Xi, R. Scholz, L. Gandini Antonio, Spectrochim. Acta, Part A 118 (2014) 987-991.

[11] J.W. Anthony, R.A. Bideaux, K.W. Bladh, M.C. Nichols, Handbook of Mineralogy, Mineral Data Publishing, Tucson, Arizona, USA, 2003.

[12] E. Dowty, Phys. Chem. Min. 14 (1987) 80-93.

[13] D.M. Adams, R.S. Armstrong, S.P. Best, Inorg. Chem. 20 (1981) 1771-1776. 